\title{
INDIRECT WRITTEN CORRECTIUE FEEDBACK, REVISION, AND LEARNING
}

\author{
Fatemeh Poorebrahim \\ University of Maragheh, Iran \\ elhampoorebrahim@yahoo.com
}

First received: 14 June $2016 \quad$ Final proof received: 12 January 2017

\begin{abstract}
Corrective feedback, the necessity of providing it, and how it should be provided has been one of the hot topics in the area of ELT. Amid continuing controversies over whether providing feedback helps L2 learners improve their writing accuracy, many research studies have been undertaken to compare the relative effectiveness of different types of feedback. However, the difference between two types of indirect corrective feedback, namely indication and indication plus location, have not been properly examined yet. Motivated to narrow this gap, this study is designed to compare two groups of Iranian learners, each revising their papers based on one of the aforementioned options. For data analysis, a series of independent samples $t$ tests were employed. The results revealed that the difference between the two groups in their reduction of errors from the original draft to the revision of each task followed a growing trend and became significant. Nonetheless, the difference in accuracy of new pieces of writing fell short of significance. Finally, it was found that error reduction in revision stage cannot be considered as learning. The results of the study, discussed in relation to that of others, implicate that the purpose for which feedback is provided is essential in determining the type of feedback; more explicit feedback is better for revising purposes while more implicit feedback is good for learning purposes.
\end{abstract}

Key words: written corrective feedback (WCF); error correction; revision; accuracy in writing

Over the last three decades, considerable attention has been paid to written corrective feedback (WCF). However, the ongoing discussions have not yet resulted in consensus on whether learners' written work should be corrected and if any correction is needed how explicit it should be. Therefore, most research papers on WCF can be divided into two groups. Besides research projects investigating whether providing WCF is beneficial or not, there is another thread of research examining the relative effectiveness of different types of WCF. Given the contradictory results in both areas, they need to be supplemented by further research before any accurate judgment could be made about the value of WCF.

A range of studies have compared different types of feedback or a combination of different types to find their relative effectiveness in accuracy of both revisions (Fathman \& Whalley, 1990; Frantzen \& Rissell, 1987; Ferris, 1997; Chaney, 1999; Komura, 1999) and subsequent writing (Truscott \& Hsu, 2008; Chandler, 2003; Liu, 2008, Frear \& Chiu, 2015). However, a limited number of these studies have dealt with indirect WCF (Ferris \& Roberts, 2001) and almost no studies, to my knowledge, have investigated the differential effects of indirect WCF options on improvement in accuracy of new pieces of writing. As Ellis (2009, p. 100) has stated that, "no study to date has compared the effects of these two indirect types of CF [on accuracy in new pieces of writing]".
The purpose of this study, which fits into the second of the categories mentioned above, is to sketch out the findings of previous related studies and report the findings of a new study. The current study, conducted in an EFL setting (Iran), is designed to examine the relative effectiveness of different indirect WCF options and examine the following hypotheses: (1) There is no difference between learners' accuracy in new pieces of writing across two different indirect written corrective feedback conditions, (2) There is no difference between learners' ability to revise their own written work across two different indirect written corrective feedback conditions, and (3) Improvement in accuracy of revisions does not translate into improvement in accuracy of new pieces of writing.

The term WCF, or simply error correction, refers to the way teachers react to learners written errors. There are different options for teachers to provide learners with WCF (Ellis, 2009; Bitchener \& Ferris, 2012). Ellis (2009) has provided a comprehensive typology of these options which includes, among others, direct and indirect techniques. In direct $\mathrm{WCF}$ the teacher provides learners with the correct form while in indirect WCF he/she indicates that some errors exist without providing the correct form. Based on him, there are two types of indirect WCF: a) the error is both indicated and located by the teacher, thus leaving the learners to only correct the errors and b) it is only indicated in the margin that whether a line 
contains error(s) or not. Thus, it is learners' responsibility to both find and correct errors.

Some researchers who have compared the effects of these two types of feedback (direct and indirect) have reported that indirect approach is more beneficial to learners (Ferris \& Helt, 2000; Lalande, 1982) or at least as good as the direct approach (Frantzen, 1995; Robb, Ross, and Shortreed, 1986).

In spite of the belief that direct WCF is more effective especially for learners with limited L2 proficiency (Van Beuningen et al., 2012), it is argued that indirect WCF is preferable to the direct option on the grounds that it engages learners in "guided learning and problem solving" (Lalande, 1982, p. 143). This requires deeper levels of processing and promotes learners' reflection on their linguistic knowledge which may foster acquisition in the long run (James, 1998; Reid, 1998).

If, based on the aforementioned research, we accept that indirect techniques are at least as helpful as the direct ones, the question which may arise is that how explicit this indirect feedback should be. Robb, Ross, and Shortreed (1986) investigated the effect of feedback salience on learners' ability in revising their written work. Although they found initial difference in accuracy favoring the correction group, these differences diminished gradually to the point that they advised against direct correction of learners' surface errors.

In a similar study, Ferris and Roberts (2001) compared learners' ability to revise their own written work based on the different feedback types they had received (indirect codded feedback, indirect feedback without coding, and no feedback). Their results showed that the two groups who had received indirect feedback outperformed the control group. Moreover, there was no difference between the two experimental groups. They finally suggested teachers to use the easier and faster technique, i.e. just underline errors.

Although Lee (1997) compared the two types of indirect correction, she just focused on learners' ability to revise their writing not their long-term gains and accuracy in new pieces of writing. She found out that when the locations of errors were determined, learners corrected more errors than when no clue was offered. In other words, finding the location of errors is more problematic for learners than correcting the errors and if learners find where the errors have occurred they can probably correct most of them. Drawing on this finding she calls into question the direct technique towards providing feedback in which the teacher provides the correction.

In a more recent and comprehensive study Truscott and Hsu (2008) examined the effect of indirect WCF on learners' accuracy of both revisions and subsequent written assignments. They found out that WCF had a significant effect on learners' ability to revise their own written work. However, its effect on learners' accuracy in subsequent writing was not substantial.

Chandler (2003) provided four groups of participants with different types of feedback: a) direct correction, b) underlining with description of error type in the margin, c) only description in the margin, and d) underlining. The results revealed that the more explicit the feedback was, the more accurate revisions the learners produced. Moreover, the correction and underlining groups excelled the other two in accuracy in new pieces of writing while there was no difference between underlining and correction group or between description and underlining description group.

In a recent study on indirect WCF, Frear and Chiu (2015) tried to find the effect of feedback focus on the accuracy of regular past tense verbs as well as total accuracy in subsequent writing. They compared three groups under three feedback conditions: indirect focused WCF, indirect unfocused WCF, and no feedback. They measured change in learners' accuracy over a three-week period and reported significant improvement in accuracy of regular past tense verbs for the two experimental groups but no change for the control one. Moreover, the two feedback groups were not substantially different in either immediate posttest or delayed posttest; however, they significantly outperformed the control group in both posttests. With regard to overall accuracy, unlike the focused group which showed a meaningful change over time, the unfocused and control groups did not improve their accuracy. In addition, although the difference between the experimental groups was not meaningful, they produced more accurate writing in both posttests than the control group.

In short, despite the abundance of studies in the area of WCF, no study, to the best of my knowledge, has compared the relative effectiveness of marginal indication and underlining types of indirect WCF on both accuracy of revisions and subsequent writing, what this study sets out to find.

\section{METHOD \\ Participants and settings}

Twenty EFL students, 10 males and 10 females, who had signed up for a general English course at a private English school, in Maragheh, Iran, participated in the study. However, the data obtained from 14 of them was used for the purpose of analysis since six learners either missed the posttest or did not hand in at least one of their written assignments/revisions.

The participants, ranging in age from 15 to 17 , were enrolled in the seventh semester of a general English course. They were assigned to two classes by the school manager based on their gender. It is worth mentioning that the participants of the study 
were bilinguals, speaking Turkish/Azari as their first language and Farsi/Persian as their second language, and were learning English as a third language.

The participants' course book was Top notch 3 by Saslow and Asher (2012). The book is designed for intermediate level learners and follows a communicative approach towards teaching English language. The course, therefore, addressed all main skills with a focus on speaking. The bulk of the class time was spent on students' engaging in whole class discussions, conversations in pairs about topics provided by their text book, and individual presentations.

Considering writing, in each semester there were four writing assignments for them to complete. In the seventh semester, in which the study was carried out, the learners wrote about the following topics: a) formal and informal email messages, b) comparison of two types of medical treatments, c) being a procrastinator: a problem or not, d) a review of a book or an article they had read. Sub-skills were also dealt with in each unit by introducing new vocabulary and presenting and explaining grammar rules by the teachers, one of them being the author of this study. Although course objectives, content, materials, and class activities were the same, the two classes were taught by different teachers. In order to achieve consistency in instruction and data collection process, the two teachers worked closely together. Each class met three times a week for about nine weeks and each session lasted for two hours with a ten-minute recess in the middle.

\section{Procedure}

Before the onset of the semester, the leaners in each class were randomly assigned to two groups using their ID numbers. This designation was used only for the purpose of determining the feedback type and was not used for the rest of class activities. At the beginning of the semester the learners were informed that they would receive different types of feedback and that their written work would be used for research purposes.

In the first session, they were given 20 minutes to write an essay of about 150 words on the benefits and the problems of the Internet. The papers were corrected by the instructor-researcher and the results were used to determine if the participants had had similar levels of writing proficiency.

At the end of each unit of the course text book the learners were given a piece of A4 paper containing some information including the writing topic and word limit. They were asked to write their paragraph(s) on the paper and submit it the next session. After receiving the first draft of the participants' written work, the instructor-researcher provided relevant feedback and calculated error rate. Then the papers were returned to the learners, who were supposed to revise them based on the given feedback and hand in both the first draft and the revision the session after that. After receiving the revisions, the researcher cross checked the first drafts and the relevant revision papers to make sure that all participants in both groups had revised their papers.

In the final session of the semester the posttest was given to the learners. They were given 20 minutes to write about how to prepare for an imminent natural disaster. The data collected at this stage was used to determine if different types of indirect WCF affected accuracy in new pieces of writing.

\section{Marking of errors}

The errors of learners in both groups were marked in red immediately after the task completion. The errors of the first group were indicated only by putting an $\mathrm{X}$ to the left of the lines containing error(s). The errors in the first drafts of the other group were both indicated and located, i.e. all errors were underlined (see Appendix for samples from each group). After the errors were marked by the instructor-researcher, the error rate, total number of errors divided by total number of words, was calculated for each piece of writing. To ensure consistency of scoring, 20 percent of the papers, which were randomly chosen and copied before correction, were corrected by the same scorer two months later. The intra-rater reliability of scoring turned out to be 89 .

The feedback provided for the learners was almost comprehensive and unfocused, meaning that all errors related to grammar and word choice were included. However, errors in mechanics of writing were ignored except for run-on sentences and fragments. Spelling errors were not counted as long as they did not change meaning. For example, the word etiquette which was misspelled as ettiquette by a learner was not considered as error but the same word written as etiquettes by another learner was marked as error. Another example is the word high school spelled as hi school. This was marked as an error since misspelling affected meaning.

\section{FINDINGS AND DISCUSSION}

Descriptive statistics, as shown in Table 1, indicate that the mean error rate of the two groups were slightly different both before and after the treatment. However, to form sound judgment the data needed to be examined using appropriate comparison procedures.

In order to decide on the best procedures for comparing the two groups, first, the data was examined to determine whether the underlying assumptions of parametric $t$ test, normality of distribution and equality of variances, were satisfied. The results of testing the assumptions revealed that the data collected through the pretest was not normally distributed for the Indication (I) 
group; however, the distribution of the data from Indication-Location (IL) group was normal. Similarly, the data collected from both groups in the posttest was normally distributed. Considering the second assumption, in the pretest the groups had equal variances, however, in the posttest the variances were not homogeneous. Based on these findings appropriate procedures, which will be elaborated on in subsequent sections, have been used for the purpose of between-group comparisons.

Table 1. Descriptive statistics for error rate of both groups in pretest and posttest

\begin{tabular}{lccccc}
\hline & Group & N & Mean & Std. Deviation & $\begin{array}{c}\text { Std. Error } \\
\text { Mean }\end{array}$ \\
\hline \multirow{2}{*}{ Pretest } & I & 7 & .04614 & .030765 & .011628 \\
\cline { 2 - 6 } \multirow{2}{*}{ Posttest } & IL & 7 & .04043 & .017915 & .006771 \\
\cline { 2 - 6 } & I & 7 & .03186 & .009512 & .003595 \\
\hline
\end{tabular}

\section{Hypothesis 1}

Since in the pretest the data was not distributed normally but variances were equal, non-parametric Mann-Whitney U test was employed to examine the difference between the two groups before the beginning of the experiment. The results showed that the difference was not meaningful $(\mathrm{p}=.902)$, i.e., the two groups had been homogeneous before the onset of the treatment.
Considering the posttest, the data gathered from both groups was normally distributed but the variances were not homogeneous. Therefore, Welch procedure, in which variances are assumed to be unequal, was used to compare the two groups to determine the effectiveness of different types of indirect WCF. The results, presented in Table 2, revealed that the difference between the two groups was not significant after the experiment.

Table 2. The results of $t$ test for the posttest

\begin{tabular}{|c|c|c|c|c|c|c|c|c|}
\hline & & \multirow{2}{*}{$\mathbf{t}$} & \multirow{2}{*}{ df } & \multirow{2}{*}{$\begin{array}{l}\text { Sig. }(2- \\
\text { tailed) }\end{array}$} & \multirow{2}{*}{$\begin{array}{c}\text { Mean } \\
\text { Difference }\end{array}$} & \multirow{2}{*}{$\begin{array}{l}\text { Std. Error } \\
\text { Difference }\end{array}$} & \multicolumn{2}{|c|}{$95 \%$ CI } \\
\hline & & & & & & & $\mathbf{L L}$ & UL \\
\hline \multirow{2}{*}{ Error rate } & $\begin{array}{l}\text { Equal variances } \\
\text { assumed }\end{array}$ & 340 & 12.00 & .740 & .003571 & .010504 & -.019315 & 026458 \\
\hline & $\begin{array}{l}\text { Equal variances } \\
\text { not assumed }\end{array}$ & .340 & 7.56 & .743 & .003571 & .010504 & -.020896 & 028039 \\
\hline
\end{tabular}

\section{Hypothesis 2}

After analyzing the data obtained through the pretest and the posttest, the data gathered from the first draft and revision of each task was analyzed. Descriptive statistics for learners' error reduction from each sample to the related revision are given in Table 3. To measure if there was a difference between the learners of the two groups in their ability to revise their own written work based on the given feedback, first reduction of error rates from each draft to the relevant revision was computed. Then, in order to determine the appropriate procedure of comparing means, the data was checked for normality of distribution and equality of variances.

Table 3. Descriptive statistics for learners' error reduction

\begin{tabular}{lccrrr}
\hline & Group & N & Mean & Std. Deviation & \multicolumn{1}{c}{ Std. Error Mean } \\
\hline \multirow{2}{*}{ Error Reduction1 } & I & 7 & .01143 & .011956 & .004519 \\
\cline { 2 - 6 } & IL & 7 & .02486 & .011880 & .004490 \\
\hline \multirow{2}{*}{ Error Reduction2 } & I & 7 & .01657 & .004315 & .001631 \\
\cline { 2 - 6 } & IL & 7 & .02800 & .012503 & .004726 \\
\hline \multirow{2}{*}{ Error Reduction3 } & $\mathrm{I}$ & 7 & .00829 & .009376 & .003544 \\
\cline { 2 - 6 } Error Reduction4 & $\mathrm{IL}$ & 7 & .02600 & .016643 & .006291 \\
& $\mathrm{I}$ & 7 & .01171 & .006525 & .002466 \\
\cline { 2 - 6 } & $\mathrm{IL}$ & 7 & .02386 & .009924 & .003751 \\
\hline
\end{tabular}

After that, four independent samples $\mathrm{t}$ tests were conducted to compare the two groups on their reduction in error rates from each sample to the relevant revision. The results are presented in Table 4. The effect size, which determines the magnitude of the difference between the two groups, was large for Error Reduction $3(\mathrm{~d}=1.31)$ and even larger for error reduction $4(\mathrm{~d}=2.70)$.
Considering the first written assignment, as Table 4 indicates, the two groups were not significantly different in their error reduction rate. Since variances of the two groups were not equal in the second writing task, using Welch procedure revealed that the difference between the two groups was not significant, either. However, from the third revision, the difference between the two groups 
started to become meaningful and in the final task the difference was the most significant. Since in Error Reduction 4 the data did not follow a normal distribution, Mann-Whitney U test was also used to compare means. The results ( $\mathrm{p}$ value $=.011)$ confirmed those of the $t$ test.

Table 4. The Results of $t$ test for error reduction from first drafts to revisions

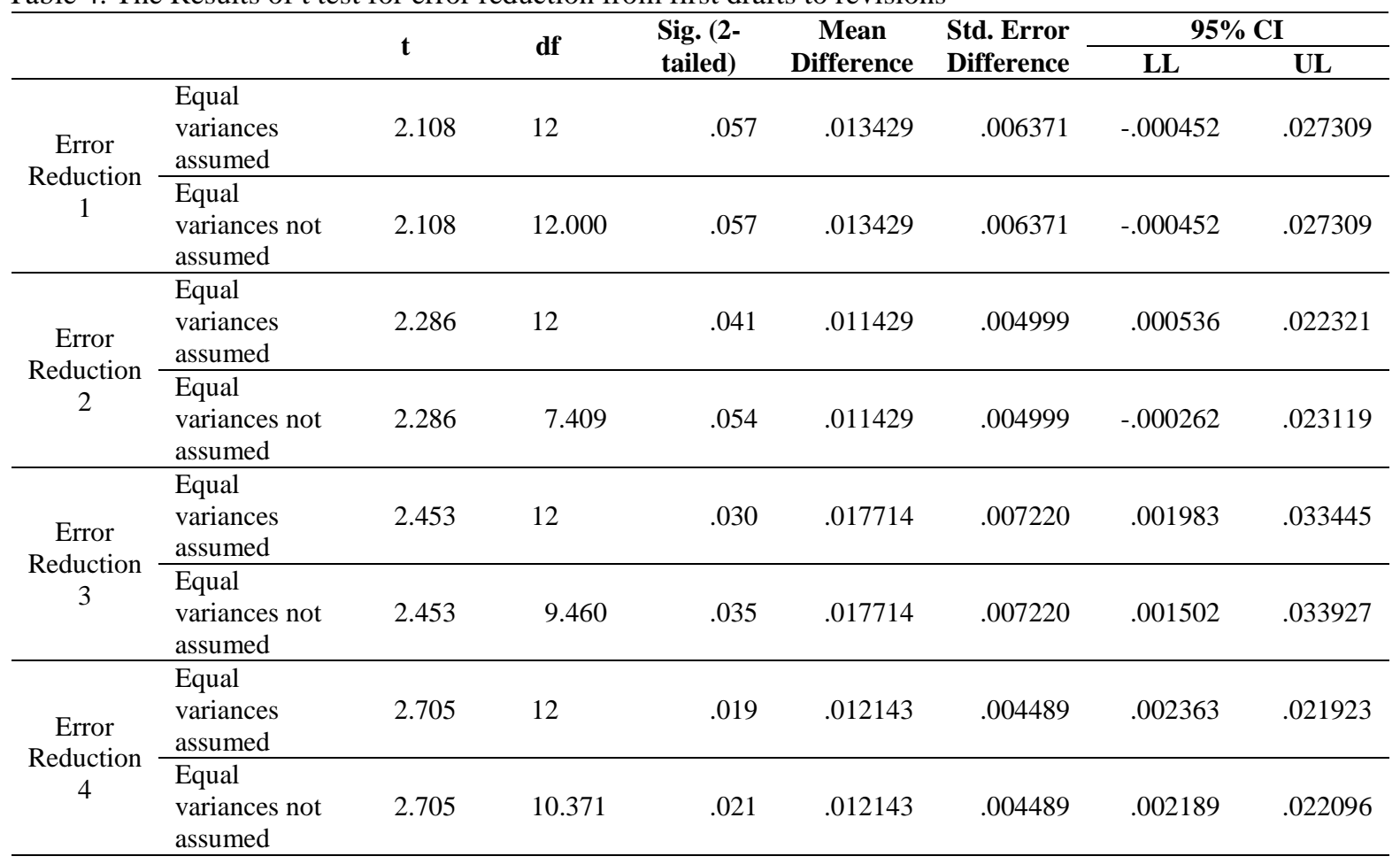

In sum, there was no significant difference between error reduction rates of the two groups in the first two tasks but in the second pair of tasks the learners who had their errors underlined were more successful in revising their errors than those whose errors were only indicated.

Hypothesis 3

In order to examine the third hypothesis, the two groups were compared in terms of average improvement of revisions as well as in the new writing task they completed in the posttest. It was previously found (results for Hypothesis 1) that there was no meaningful difference between IL (M= $.028, \mathrm{SD}=.026)$ and $\mathrm{I}(\mathrm{M}=.31, \mathrm{SD}=.009)$ groups in the posttest; $\mathrm{t}(12)=.340, \mathrm{p}=.74$.

To calculate the average improvement in accuracy of revisions, first, the mean of error reduction rates from first tasks to revisions was computed. Since the data satisfied underlying assumptions of parametric tests, an independent samples $\mathrm{t}$ test was conducted to compare the two groups. The results, presented in Table 5, indicate a significant difference between IL group $(\mathrm{M}=.084$, $\mathrm{SD}=.036)$ and I group $(\mathrm{M}=.039, \mathrm{SD}=.009)$. In other words, the group whose errors were underlined, on average, corrected more errors than the other group in the revision stage.

The data was also examined qualitatively. In the participants' compositions, there were many cases of using incorrect prepositions. The least improvement, if any, from the pretest to the posttest seem to have been in this sub-category of grammar, prepositions. Some participants even had more mistakes related to prepositions in the posttest than the pretest.

Table 5. The results of $\mathrm{t}$ test for average error reduction

\begin{tabular}{|c|c|c|c|c|c|c|c|c|}
\hline & & \multirow{2}{*}{$\mathbf{t}$} & \multirow{2}{*}{ df } & \multirow{2}{*}{$\begin{array}{l}\text { Sig. (2- } \\
\text { tailed) }\end{array}$} & \multirow{2}{*}{$\begin{array}{c}\text { Mean } \\
\text { Difference }\end{array}$} & \multirow{2}{*}{$\begin{array}{l}\text { Std. Error } \\
\text { Difference }\end{array}$} & \multicolumn{2}{|c|}{$95 \% \mathrm{CI}$} \\
\hline & & & & & & & $\mathbf{L L}$ & UL \\
\hline \multirow{2}{*}{$\begin{array}{l}\text { Average } \\
\text { error } \\
\text { reduction }\end{array}$} & $\begin{array}{l}\text { Equal variances } \\
\text { assumed }\end{array}$ & 3.086 & 12.000 & .009 & .04561 & .01478 & .01341 & .07781 \\
\hline & $\begin{array}{l}\text { Equal variances } \\
\text { not assumed }\end{array}$ & 3.086 & 7.422 & .016 & .04561 & .01478 & .01106 & .8015 \\
\hline
\end{tabular}

Note. $\mathrm{CI}=$ confidence interval, $\mathrm{LL}=$ lower limit, $\mathrm{UL}=$ upper limit.

Word order rules were also violated, mostly in embedded questions. For instance, one participant used the sentence "some people don't know how should they make a schedule for their works". This structure (embedded questions) had been taught in the semester the experiment was done. The results 
of formative assessment during the term showed that most of the participants had learnt this structure. That is, the participants could choose the correct option in multiple choice questions and also recognize mistakes and correct them in sentences where embedded questions were used incorrectly. This, knowing structures but using them incorrectly in composition, may have been the result of decontextualized instruction of grammar rules. In the course books taught at both mainstream schools and private institutes, writing has received the least attention and students are not sufficiently required to use their grammar knowledge to produce accurate texts. At school, their written production is restricted to sentence level writing. At private institutes, besides sentence production, they are also required to produce paragraphs, but the number of the compositions they produce does not seem to be enough (about 4 writing tasks in a period of 2 months).

Many grammatical errors of all types committed in first drafts were corrected by the IL group in the revisions, especially in the revisions of the third and fourth writing tasks. The participants of the other group, I, on the other hand, could correct fewer mistakes. While the revisions made by the IL group were more accurate and to the point, the revisions made by the I group seemed not to have been purposeful. In other words, the IL group, in most cases, made changes only to the underlined word(s) while the I group mostly changed groups of words and in some cases they completely changed the sentences which were marked as containing grammatical errors. This is most likely to have resulted from their not knowing which part of the Indicated sentence was erroneous. It is also worth mentioning that the I group seemed to have improved the content of their revisions and used more appropriate vocabulary as compared to their first drafts. However, as mentioned earlier, the IL group was better in accuracy improvement of the third and fourth revisions but the two groups were not different in the accuracy of new pieces of writing.

In short, the results of the statistical analysis revealed that different types of indirect WCF did not have a significant effect on learners' accuracy in new pieces of writing. However, examining error reduction rate from the first draft to the revision of each assignment revealed that the difference between the two groups followed a growing trend although in the first two written assignments the difference was not big enough to be considered as significant. That is, neither of the two error feedback types had been more effective than the other in helping learners fix their errors in the revision stage of the first two tasks. Differences started to become significant between the two groups in the third task and became larger in the fourth one. This might be explained by the close nature of the feedback options used in this study. It seems more logical to expect differences between learners' performance in early stages when there is a substantial difference between the explicitness level of the feedback types given than when the difference is subtle. Therefore, the more similar the feedback types are, the more time and perhaps tasks may be needed for differences in accuracy of revisions to emerge or become significant.

Comparing Ferris and Roberts's (2001) study with this study supports the idea that treatment duration may affect the results of the study. They compared performance of participants under three different conditions of underlining, underlining plus coding, and no feedback. The difference between the two experimental groups' revising ability was not significant enough to justify more time spent on providing feedback by the teacher. Therefore, they finally concluded that underlining, which is less explicit and hence easier and faster, is more appropriate. This study replicates their results in that the difference between the two groups was not significant in the first two revision tasks which were fulfilled in the first month of the treatment. However, the results depart from theirs in the second two tasks. The difference between the two groups became statistical in the third and fourth tasks which were carried out in the second month. The non-significant difference in participants' revising ability in Ferris and Roberts's (2001) study and the initial assignments of this study might be related to the temporal nature of the studies. The conclusion they have drawn is based on a study of two weeks, which may not be enough for differences to emerge. As seen in this study, experiment length has a direct effect on the findings of WCF studies.

In addition to treatment length the number of tasks learners perform seem to be of crucial importance. Robb, Ross, and Shortreed (1986), who compared the effectiveness of four different types of WCF on accuracy of revisions, reported results similar to those of Ferris and Roberts (2001). Finding no difference between the performance of the subjects in different groups, they concluded that "less time consuming methods of directing student attention to surface errors may suffice" (Robb, Ross, \& Shortreed, 1986, p. 91). Although their study took about eight months, the participants produced only five pieces of writing which may not have been enough in an eight-month period for the differences to emerge. Considering the abovementioned, the results of many short-term studies can be used with more certainty if they are replicated by longer-term longitudinal ones.

The results of this study can also be discussed in the light of findings from other studies. Chandler (2003), for example, found a direct relationship between the level of feedback explicitness and reduction of errors in revision stage. Similarly, in 
this study the learners who received the more explicit feedback option, IL group, outperformed the group whose errors were only indicated in the margin (I). This study and that of Chandler (2003) are also partly similar considering improvement in accuracy over time. Although she found a significant difference between accuracy improvement of learners who had received either description or underlining with description and that of those receiving either correction or underlining, she reported that the difference between correction and underlining groups (which received feedbacks of different levels of explicitness) were not statistical. This is in line with the findings of the current study in which the written accuracy of the experimental groups did not change over a twomonth period.

The third research hypothesis can be discussed in the light of Truscott and Hsu's (2008) study. In a one-week-long study they reported results similar to the findings of this study. They found significant differences in revising ability of a group who had their errors underlined and a control group. However, their participants did not differ statistically in subsequent independent writing. Therefore, along their line of discussion, it seems that improvement in accuracy of revisions may not translate into learning as measured by accuracy of independent subsequent writings (at least under the conditions and with participants similar to those of the present study) unless longer-term longitudinal studies in future prove otherwise. Therefore, for the time being and based on existing evidence, the results of revision studies should perhaps be used more cautiously when discussing and evaluating the effectiveness of different types of WCF on accuracy in subsequent pieces of writing.

From a theoretical point of view, the results can be discussed in relation to those of Frear and Chiu (2015). The findings of their study give more support to Swain's (1995) pushed output than Schmidt's noticing hypothesis (1990) and noticing with metalinguistic understanding (2001). They state that "the WCF served as a trigger for the learners to push their overall accuracy when completing the immediate post-test writing task and the delayed post-test writing task." (p. 32). On the other hand, Sheen, Wright, and Moldawa (2009) attributed accuracy improvement in their study to learners' becoming aware of target structures and noticing them.

Considering that in the study presented here the feedback given to learners has been both indirect and unfocused, and therefore less likely to have resulted in learners noticing target structures and yet accuracy has slightly improved in both revisions and new pieces of writing (although sometimes not statistical enough) it seems to be reasonable to conclude that accuracy improvement has not been a result of noticing. Perhaps WCF has helped learners push their output to improve their writing.

\section{CONCLUSION}

Based on the findings of this study, EFL teachers and practitioners are advised to choose corrective feedback type depending on the purpose for which the feedback is given. When they intend to help learners edit and revise their written work, more explicit feedback options are more profitable. However, if the purpose is to help learners improve their knowledge, more implicit types of feedback are more helpful. The advantage of using more implicit feedback when the purpose is learning is twofold. For teachers, providing implicit feedback is less time consuming. For learners, revising becomes more of a problem solving task which is more likely to promote learning.

Like many other studies, this study has its own limitations, some of which can be addressed by further research. Although in this study both experiment duration and number of writing tasks were more than many other studies, it seems that they have not been enough. For example, the difference between the two groups' accuracy in neither the pretest nor the posttest was statistical; however, in the posttest as compared to the pretest the mean error rate difference became smaller (see Table 1). In other words, the IL group has improved its accuracy more than the I group. Further research with more independent writing tasks (and preferably longer-term) can shed more light on whether this difference continues to become smaller and whether the relationship becomes reverse at some point. If this is proved by future research, then less time consuming WCF options, as they are sometimes suggested as more appropriate, may not be always recommendable.

Up to now, this study and that of Truscott and Hsu (2008) have shown that learners' ability to improve accuracy of revisions based on the WCF they have received is not indicative of learning. However, drawing firm conclusions based on only two studies does not seem to be safe. Therefore, more studies are needed to investigate the validity of using revision studies in interpreting the findings of research on effectiveness of feedback.

Since, based on evidence from this study, learners' ability to revise, even using indirect WCF which is more likely to result in learners pushing their knowledge to the outer limit (Frear \& Chiu, 2015), does not constitute improvement of future writing, it seems that meta-analysis studies designed to investigate effectiveness of WCF are more likely to yield more reliable results if they exclude findings of revision studies.

In this study it was found that underlining learners' written errors is more profitable than marginal indication of errors when the purpose of giving feedback is helping learners revise their own 
written work. On the other hand, there was no difference between these two indirect options of providing feedback as to accuracy improvement in new pieces of writing. It is also discussed that improvement in accuracy of revisions might not be a good predictor of learning as measured by accuracy in later independent writing tasks. However, as discussed in the discussion section, treatment length and learners' written production rate may exert considerable influence on the results. Therefore, the results should be used cautiously until further research sheds more light on the issue under discussion.

\section{REFERENCES}

Bitchener, J. \& Ferris, D. (2012). Written corrective feedback in second language acquisition and writing. London: Routledge.

Chandler, J. (2003). The efficacy of various kinds of error feedback for improvement in the accuracy and fluency of L2 student writing. Journal of Second Language Writing, 12, 267296.

Chaney, S. J. (1999). The effect of error types on error correction and revision. MA thesis, Department of English, California State University, Sacramento.

Ellis, R. (2009). A typology of different corrective feedback types. ELT, 63(2), 97-107.

Fathman, A., \& Whalley, E. (1990). Teacher response to student writing: Focus on form versus content. In B. Kroll (Ed.), Second language writing: Research insights for the classroom (pp. 178- 190). Cambridge: Cambridge University Press.

Ferris, D. R. (1997). The influence of teacher commentary on student revision. TESOL Quarterly, 31(2), 315-339.

Ferris, D. R., \& Helt, M. (2000). Was Truscott right? New evidence on the effects of error correction in L2 writing classes. Paper presented at the AAAL Conference, Vancouver, B.C.

Ferris, D. R., \& Roberts, B. (2001). Error feedback in L2 writing classes: How explicit does it need to be? Journal of Second Language Writing, 10(2), 161-184.

Frantzen, D. (1995). The effects of grammar supplementation on written accuracy in an intermediate Spanish content course. Modern Language Journal, 79(3), 329- 344.

Frantzen, D., \& Rissell, D. (1987). Learner selfcorrection of written compositions: What does it show us? In B. VanPatten, T. R. Dvorak, \& J. F. Lee (Eds.), Foreign language learning: A research perspective (pp. 92-107). Cambridge:
Newbury House.

Frear, D., \& Chiu, Y-H. (2015). The effect of focused and unfocused indirect written corrective feedback on EFL learners' accuracy in new pieces of writing. System, 53, 24-34.

James, C. (1998). Errors in language learning and use: Exploring error analysis. London: Longman.

Komura, K. (1999). Student response to error correction in ESL classrooms. MA thesis, Department of English, California State University, Sacramento.

Lalande, J. F., II (1982). Reducing composition errors: An experiment. Modern Language Journal, 66(2), 140- 149.

Lee, I. (1997). ESL learners' performance in error correction in writing. System, 25(4), 465-77.

Liu, Y. (2008). The effects of error feedback in second language writing. Arizona Working Papers in SLA \& Teaching, 15, 65-79.

Reid, J. (1998). Responding to ESL student language problems: Error analysis and revisions plans. In P. Byrd, \& J. M. Reid (Eds.), Grammar in the composition classroom: Essays on teaching ESL for college-bound students (pp. 118- 137). Boston: Heinle \& Heinle.

Robb, T., Ross, S., \& Shortreed, I. (1986). Salience of feedback on error and its effect on EFL writing quality. TESOL Quarterly, 20, 83-93.

Saslow, J., \& Ascher, A. (2011). Top Notch Fundamentals second edition. New York: Pearson Education.

Schmidt, R. (1990). The role of consciousness in second language learning. Applied Linguistics, 11(2), 17-46.

Schmidt, R. (2001). Attention. In P. Robinson (Ed.), Cognition and second language instruction.

Cambridge: Cambridge University Press.

Sheen, Y., Wright, D., \& Moldawa, A. (2009). Differential effects of focused and unfocused written correction on the accurate use of grammatical forms by adult ESL learners. System, 37(4), 556-569.

Swain, M. (1995). Three functions of output in second language learning. In G. Cook, \& B. Seidlhofer (Eds.), Principle and practice in applied linguistics (pp. 125-144). Oxford: Oxford University Press.

Truscott, J \& Hsu, A. Y. (2008). Error correction, revision, and learning. Journal of Second Language Writing, 17(4), 292-305.

Van Beuningen, C. G., De Jong, N., \& Kuiken, F. (2012). Evidence on the effectiveness of comprehensive error correction in second language writing. Language Learning, 62(1), $1-41$. 


\section{Appendix}

Sample 1: Errors are only indicated

$\mathrm{X}$ In my opinion, if you're not a well-organized, you're going to have a lot of problems in life.

$\mathrm{X}$ Procrastinators tend to put things off and I think no one would like to live with such a this person. Whenever you procrastinate things, you must be ready for a bad punishment.

$\mathrm{X}$ Frankly, I used to be a kind of procrastinator. When I was younger, I often forgot to do

$\mathrm{X}$ some of my homeworks and also I forgot to buy a gift for some of my friends birthday. But fortunately, I've changed a lot and I'm usually on time in everything I do. For instance, I

$\mathrm{X}$ always try to be the first one who congratulates others' birthday and every time I forgot

$\mathrm{X}$ doing things, I feel terrible.

$\mathrm{X}$ From my point of view it's very good to be a well-organized. Being a procrastinator keeps a

$\mathrm{X}$ person from getting things done. For example, at work my colleague has a hard time with

$\mathrm{X}$ coping documents and reports and tends to do them all at the last minute. So she can't do them at all or even get them done, because on that time there will be no copy-shop available. So you see, it must be very easy to put things off. In contrast, the result isn't that much easy at all!

Sample 2: Errors are both indicated and located (underlined)

In my humble opinion, being a procrastinator is strongly related to our personality, but we can change from being a procrastinator person to being a well-organized and helpful person for our society while it's not as easily as we think. If you are a procrastinator, you should think about very changes in your life. First of all, let me say something to you about myself. When I was a child, I was a procrastinator and I did my works very late or even I didn't do it, I didn't have any plan and I tended to put things off. But one day, I started to be a well-organized person and I tried a lot and now I'm satisfied with my trying.

Do you want to know how I've became a well-organized person? Sure you want to know. I will give you three ways to become a well-organized person. At the first, don't say that you will do your work tomorrow. For instance, don't say that the summer is very long and you will have a lot of time to study or you will study next week. Second, plan for your days or weeks. Don't do anything without planning. Finally, carry out your plan. Do what you have been planned, such as playing, studying, working and .... . If you do what I've told you, you will be a wellorganized person. 